\title{
The effect of protein types and low molecular weight surfactants on spray drying of sugar-rich foods
}

\author{
M. Jayasundera ${ }^{\text {a }}$, B. Adhikari ${ }^{\mathrm{a}, *}$, R. Adhikari ${ }^{\mathrm{b}}$, P. Aldred ${ }^{\mathrm{a}}$ \\ ${ }^{a}$ School of Science and Engineering, University of Ballarat, Mount Helen, Vic 3350, Australia \\ ${ }^{\mathrm{b}}$ CSIRO Molecular and Health Technologies, Clayton South, Vic 3169, Australia
}

\section{A R T I C L E I N F O}

\section{Article history:}

Received 25 March 2010

Accepted 22 July 2010

\section{Keywords:}

Sugar-rich foods

Stickiness

Sodium caseinate

Pea protein isolate

LMS

Spray drying

\begin{abstract}
A B S T R A C T
The effect of protein types and low molecular weight surfactants (LMS) on spray drying of sugar-rich foods has been studied using sucrose as a model sugar and sodium caseinate (NaCas) and pea protein isolate(PPI) as model proteins. Sodium stearoyl lactylate (SSL) and Polysorbate 80 (Tween-80) were chosen as model ionic and non-ionic LMS. The sucrose:NaCas and sucrose:PPI solid ratios were maintained at (99.5:0.5) and (99:1), respectively and spray-dried maintaining $25 \%$ solids in feed solutions. It was found that the proteins preferentially migrated to the air-water interface reasonably swiftly and the addition of LMS resulted into partial or complete displacement of the proteins from the air-water interface. More than $80 \%$ of amorphous sucrose powder was produced with the addition of $0.13 \%(\mathrm{w} / \mathrm{w})$ of NaCas in feed solution. PPI was not as effective and produced less than $50 \%$ recovery even at $0.26 \%(\mathrm{w} / \mathrm{w})$ in feed. Addition of $0.01-0.05 \%$ SSL displaced $2.0 \%$ and $29.3 \%$ of proteins from the surface of sucrose-NaCas-SSL droplet, respectively, resulting in a $6.5 \pm 1.2 \%$ to $51.9 \pm 1.9 \%$ reduction in powder recovery. The extent of protein displacement was higher when SSL was added into sucrose-PPI solution; however, the powder recovery was not much affected. The addition of $0.01 \%$ Tween- 80 in sucrose-NaCas solution resulted in a $48.2 \pm 1.5 \%$ reduction in powder recovery and at $0.05 \%$ concentration, it displaced a substantial amount or all the NaCas from the droplet surface and no powder was recovered. The addition of $0.01 \%$ and $0.05 \%$ Tween- 80 into sucrose-PPI solution resulted into very low powder recoveries $\left(24.9 \pm 0.4 \%\right.$ and $29.5 \pm 1.8 \%$, respectively). The glass transition temperature $\left(\mathrm{T}_{\mathrm{g}}\right)$ results revealed that the amount of protein required for successful spray drying of sucrose-protein solutions depends on the amount of proteins present on the droplet surface but not on the bulk concentration. X-ray diffraction and scanning electron microscopy results showed that the powders of sucrose-NaCas/PPI and sucrose-NaCas/PPI with $0.01 \%$ SSL were mostly amorphous while those with sucrose-NaCas/PPI-Tween80 (0.01\%), sucrose-PPI-Tween-80 (0.05\%) and sucrose-NaCas/PPI-SSL (0.05\%) were crystalline.
\end{abstract}

() 2010 Elsevier Ltd. All rights reserved.

\section{Introduction}

Spray drying is a well-established and widely used method for transforming a wide range of liquid food products into powder form. The process involves spraying finely atomized solutions into a chamber where hot and dry air rapidly evaporates the solution leaving the spray-dried particles. Spray-dried powders can be stored at ambient temperature for prolonged periods without compromising the powder stability. They are also cheaper to transport and easier to handle in manufacturing plants. Spray-dried powders are economical to produce compared to other processes

\footnotetext{
* Corresponding author. Tel.: +61 3 53279249; fax: +61353279240.

E-mail address: b.adhikari@ballarat.edu.au (B. Adhikari).
}

such as freeze-drying (Knorr, 1998). Spray drying has many applications, particularly in the food, pharmaceutical and agrochemical industries (Adhikari, Howes, Shrestha, \& Bhandari, 2007; Maa \& Hsu, 1997; Maa, Nguyen, \& Hsu, 1998; Vega, Goff, \& Roos, 2005).

There are many food products that have very high sugar and organic acid contents and there is a growing interest to convert them into more useable and stable forms such as powders (Bhandari, Datta, \& Howes, 1997). Conversion of high value food materials such as fruit and vegetable extracts and honey into particulate form is not easy due to the presence of a high proportion of low molecular weight sugars in their composition (Adhikari et al., 2007). This is because these constituents have a low glass temperature $\left(T_{g}\right)$ which is the main reason for stickiness (Vega et al., 2005).

The stickiness problem causes considerable economic loss and limits the application of drying techniques, such as spray drying, for 
food and as well as pharmaceutical materials (Boonyai, Bhandari, \& Howes, 2004; Maa \& Hsu, 1997; Maa et al., 1998). To minimize the stickiness problem, process and material-science-based approaches are in place. Process-based approaches include: the mechanical scraping of the chamber wall; introduction of cold air at the bottom; and, the use of low temperature low humidity air. Changing the glass transition temperature of feed solution by the introduction of drying-aids is an example of the material-science-based approach (Downton, Flores-Luna, \& King, 1982). Process-based modifications are not easy and can be economically non-viable. For example, stickiness could be avoided by keeping the outlet temperature of air below $50{ }^{\circ} \mathrm{C}$ or even at ambient temperature; however the production becomes economically non-viable. The materialscience-based approach also has its own limitations. Large amounts of drying additives such as maltodextrins ( $>35 \%$ ) are required to convert fruit juices such as blackcurrant, apricot and raspberry into powder form (Gabas, Telis, Sobral, \& Telis-Romero, 2007; Righetto \& Netto, 2005; Tonon et al., 2009). Addition of such large amounts of these carriers alters the resultant powder quality and risks consumer disapproval.

An alternative and novel way to minimize the stickiness problem is to modify the surface properties of the droplets/particles with small amounts of proteins (Adhikari, Howes, Bhandari, \& Langrish, 2009). It was found that the preferential migration of proteins combined with their film-forming property upon drying, is responsible for overcoming the stickiness of sugar-protein solutions (Adhikari, Howes, Bhandari, et al., 2009). Proteins from legume seeds have been widely studied with regard to functional and bioactive properties and are considered important for novel food development and for human health (Pereira et al., 2009). The relationship between physicochemical characteristics and interfacial behaviour on oligomeric plant proteins (pea legumin) was investigated by Subirade, Gueguen, and Schwenke (1992). They found that the molecular properties of oligomeric seed proteins, particularly size, net charge and conformational characteristics are important in controlling the surface activity. Although there are a few studies reported on surface modification of sugar-rich foods with dairy proteins such as whey protein and sodium caseinate (Adhikari, Howes, Bhandari, et al., 2009), there is no comparative research on the efficacy of plant proteins in the modification of surface properties of droplets/particles of sugar-rich foods.

It is known that both protein and LMS compete for the air-water interface of a droplet (Mackie, Gunning, Wilde, \& Morris, 2000; Pugnaloni, Dickinson, Ettelaie, Mackie, \& Wilde, 2004; Rouimi, Schorsch, Valentini, \& Vaslin, 2005; van Aken, 2003). Since LMS are smaller in size compared to proteins, the LMS are kinetically advantaged to occupy the surface of a droplet (van Aken, 2003). The effect of two low molecular weight surfactants (LMS) namely, sodium dodecyl sulphate and Polysorbate 80 along with proteins (whey protein and sodium caseinate) on spray drying of sugar-rich foods was studied (Adhikari, Howes, Wood, \& Bhandari, 2009). However, no studies have been reported on plant proteins such as PPI along with LMS in the surface modification of sugar-rich foods.

Therefore, this study was aimed to investigate the effect of protein types (NaCas and PPI) and low molecular weight surfactants (LMS) on spray drying of sugar-rich foods.

\section{Materials and methods}

\subsection{Materials}

Sucrose with 99.5\% purity (Sigma-Aldrich, Australia) was used as a model sugar-rich food. A dairy protein (NaCas) with a protein content of 92.9\% (MG 2972, MG Nutritionals, Australia) and a plant protein (PPI) with a protein content of $90 \%$ (MyoPure, Australia) were used as received. Two food grade surfactants, sodium stearoyl lactylate (SSL) and Polysorbate 80 (Tween-80) were used as model surfactants. The former (Grindsted ${ }^{\circledR}$ SSL P 60 Veg) was purchased from Danisco, Denmark, while the latter was purchased from Sigma-Aldrich, Australia. SSL is an ionic surfactant which has a lower molecular weight $(451.6 \mathrm{~g} / \mathrm{mol})$ and a comparatively higher hydrophile-lipophile balance (HLB) value of 22 while Tween-80 is a non-ionic surfactant with comparatively larger molecular weight (1310 g/mol) and a lower HLB (15) value. Both the surfactants are suitable for oil-in-water emulsions (McClements, 2005).

\subsection{Methods}

\subsubsection{Solution preparation}

The sugar-protein solutions were prepared by heating the solution at $45 \pm 5{ }^{\circ} \mathrm{C}$ and gently agitating it with a magnetic stirrer. The sucrose:NaCas solid ratio was maintained at 99.5:0.5 while it was 99:1 in the case of sucrose:PPI solution on a dry solid basis. Since our preliminary experiments showed that no powder was recovered from sucrose:PPI (99.5:0.5) solution, hence the ratio of 99: 1 was chosen. The total solid content was fixed at $25 \% \mathrm{w} / \mathrm{w}$. The initial bulk protein concentration in sucrose-NaCas was $0.13 \%$ while it was $0.26 \%$ in the case of sucrose-PPI solution. Both pre-weighed sucrose and protein were dry mixed thoroughly before addition of water. Three hundred gram solution batches were prepared. The inherent moisture content of crystalline sucrose was taken as zero while it was determined and compensated for both NaCas and PPI. Solutions of sucrose-protein-SSL and sucrose-protein-Tween-80 were prepared by adding $0.01 \%$ and $0.05 \%$ of each surfactant to the sucrose-protein solutions. The solutions were heated to $45 \pm 5{ }^{\circ} \mathrm{C}$ to ensure that all solids were completely dissolved. The solutions so prepared were tested for dynamic surface tension and subsequently spray dried.

\subsubsection{Powder production}

Spray drying of solutions was carried out on a bench-top spraydryer (Buchi B-290, Buchi, Switzerland) with a water evaporating capacity of $1 \mathrm{l} / \mathrm{h}$. The inlet and outlet temperatures were maintained at $165^{\circ} \mathrm{C}$ and $65^{\circ} \mathrm{C}$, respectively. The air flow rate was maintained at $36 \mathrm{~m}^{3} / \mathrm{h}$ while the aspiration was of $100 \%$. The powders were collected from cyclone and the cylindrical part of the dryer chamber by lightly sweeping the chamber wall as proposed by Bhandari et al. (1997). The yield was calculated as the ratio of the mass of solids collected to the mass in feed solution on a dry basis.

\subsubsection{Moisture}

The moisture content was determined by drying the powder samples in a vacuum oven (Thermoline Scientific, Australia) at $70^{\circ} \mathrm{C}$ for $24 \mathrm{~h}$ (Adhikari, Howes, Wood, et al., 2009). Samples were allowed to cool to room temperature in desiccators containing silica gel.

\subsubsection{Water activity}

Water activity of powder samples was determined using a precalibrated water activity meter (Novasina, Switzerland). The temperature was maintained at $24.5 \pm 0.5^{\circ} \mathrm{C}$.

\subsubsection{Glass transition temperature $\left(T_{g}\right)$}

Glass transition temperature of all powders was measured using thermo-mechanical compression test (TMCT). Differential scanning calorimeter (DSC) was used in representative samples to compare the results obtained through the TMCT method.

TMCT measures the changes in particle bed compressibility at a constant stress (30.6 kPa) due to softening of the powder particles, which can be linked to the glass transition temperature of bulk 
powders. Differential scanning calorimetry (DSC) is usually used for the determination of $\mathrm{T}_{\mathrm{g}}$ of food powders (Kalichevsky \& Blanshard, 1993; Sandoval, Alejandro, Müller, Valle, \& Lourdin, 2009). However, determination of $T_{g}$ of sugar-protein system by DSC is difficult due to the fact that change in specific heat capacity is small and the signal is usually masked in the thermogram (Jayasundera, Adhikari, Adhikari, \& Aldred, 2010). It is also reported that since sugar-protein is an incompatible system, the $T_{g}$ of the system measured by DSC is usually dominated by the $T_{g}$ of the sugar (Kalichevsky \& Blanshard, 1993). It is proven that the $\mathrm{T}_{\mathrm{g}}$ data obtained by TMCT corresponds to the end-point $\mathrm{T}_{\mathrm{g}}$ values measured by DSC. The details regarding the structure function and the measurement protocols are provided elsewhere (Boonyai et al., 2004; Shrestha, Ua-arak, Adhikari, Howes, \& Bhandari, 2007).

Differential scanning calorimetry (DSC) analysis was carried out over the temperature range of $-20^{\circ} \mathrm{C}$ to $180^{\circ} \mathrm{C}$ using Mettler DSC028 (Mettler Toledo, USA). The experiments were carried out at a heating rate of $10{ }^{\circ} \mathrm{C} / \mathrm{min}$ under nitrogen. Sample weights ranged between 10 and $15 \mathrm{mg}$ and were conditioned at room temperature prior to analysis (Roos \& Karel, 1991).

\subsubsection{Particle size/particle size distribution}

The particle size and size distribution were measured using a Malvern Laser Diffraction Particle size analyser (Mastersizer 2000). The volume mean diameter was selected to express the particle size as it is one of the most commonly reported particle sizes in spray-dried powders (Adhikari, Howes, Bhandari, et al., 2009). Particle size range is expressed as the 50\% volume-based size. Sunflower oil was used as a dispersing medium for all the powders. The refractive index of the oil was between 1.461 and 1.468 (O'Brien, 2009). The powder samples in oil were subjected to sonication for better dispersion of the powders.

\subsubsection{X-ray diffraction (XRD)}

XRD studies were carried out on a Siemens (D501) Diffractometer with CoK $\alpha 1$ radiation. An anti-scatter slit of $0.15 \mathrm{~mm}$ and $1^{\circ}$ divergence and receiving slits were used. Diffractograms were taken between 8 and $52.15^{\circ}(2 \theta)$ at a rate of $1.20^{\circ} / \mathrm{min}(2 \theta)$ and with a step size of $0.05^{\circ}(2 \theta)$. Diffractograms of sucrose-NaCas, sucrose-PPI, sucrose-NaCas-surfactant and sucrose-PPI-surfactant powders were obtained.

\subsubsection{Electron spectroscopy for chemical analysis (ESCA)}

Surface elemental composition of spray-dried powders was estimated by electron spectroscopy for chemical analysis (ESCA) (Fäldt, Bergenståhl, \& Carlsson, 1993). Firstly, ESCA measurements for sucrose, NaCas, PPI, SSL and Tween-80 were carried out to determine the surface composition of these materials. It is assumed that surface elemental composition of pure materials is the same as its bulk elemental composition. Secondly, the surface elemental composition of all spray-dried powders was determined. The samples were degassed for $72 \mathrm{~h}$ before subjecting them to ESCA. The ESCA analysis was performed using an AXIS-HSi spectrometer (Kratos Analytical) with a monochromatic $\mathrm{Al} \mathrm{K \alpha}$ source at a power of $144 \mathrm{~W}(12 \mathrm{kV}$ and $12 \mathrm{~mA})$, and a standard aperture of $1 \mathrm{~mm} \times 0.5 \mathrm{~mm}$. The total pressure in the main vacuum chamber during analysis was of the order of $10^{-8}$ mbar. Spectra were recorded at an emission angle of $0^{\circ}$ with respect to the surface normal with corresponding depths of penetration on the order of 5-10 $\mathrm{nm}$ (depending on the kinetic energy of the respective photoelectrons). A survey spectrum was performed to identify all elements present (acquired at a pass energy of $320 \mathrm{eV}$ ), before a high resolution $\mathrm{C} 1 \mathrm{~s}$ scan at $40 \mathrm{eV}$ pass energy was undertaken to obtain more detailed information about the chemical structure. The atomic concentrations of the detected elements were calculated using integral peak intensities and the sensitivity factors supplied by the manufacturer. Peak assignments are based on the measured binding energy values (charge-corrected with respect to the main (aliphatic hydrocarbon) peak at $285.0 \mathrm{eV}$ ). The data from the $\mathrm{C} 1 \mathrm{~s}$ high resolution spectra was quantified using a minimization algorithm to determine the contributions from specific functional groups (spectral curve fitting). Five peak components (mixed Gaussian/Lorentzian model functions) were used. Component $\mathrm{C} 1$ at the lowest binding energy (BE) was assumed to represent aliphatic hydrocarbons ("neutral" carbon) and the corresponding BE was set accordingly to $285.0 \mathrm{eV}$. A second component at a slightly higher BE was included to account for all $\mathrm{C} 1 \mathrm{~s}$ photoelectrons that underwent a secondary BE shift. Component C3 at 286.3-286.6 eV represents $\mathrm{C}-\mathrm{N}$ and $\mathrm{C}-\mathrm{O}$ based groups (e.g., amines, ethers, and alcohols), C4 at $287.9-288.2 \mathrm{eV}$ accounts for all $\mathrm{C}=\mathrm{O}, \mathrm{O}-\mathrm{C}-\mathrm{O}$ and $\mathrm{N}-\mathrm{C}=\mathrm{O}$ based groups (e.g., carbonyls, amides), and C5 at $288.9-289.3 \mathrm{eV}$ represents $\mathrm{O}-\mathrm{C}=\mathrm{O}$ based groups (e.g., acids or esters). A detailed description of ESCA as a method to measure the surface composition of dairy based food powders can be obtained from various sources (Adhikari, Howes, Wood, et al., 2009; Fäldt et al., 1993). As nitrogen is not present in sucrose and surfactants, the surface protein coverage can be calculated from a simple nitrogen balance.

\subsubsection{Scanning electron microscopy (SEM)}

All spray-dried powders were observed under a scanning electron microscope (JSM 6300 SEM). Samples were directly deposited on carbon conductive tape on aluminium SEM stubs and were coated with a thin gold layer, using gold sputtering.

\subsubsection{Dynamic surface tension (DST)}

DST measurements of individual sugar, protein and surfactant solutions and the solutions of sucrose-protein and sucroseprotein-surfactant were obtained using the Sinterface PAT-1 tensiometer (Sinterface Technologies, Germany). Surface tension indicates the tendency of molecules to move preferentially to the air-droplet interface and it can be either dynamic or equilibrium. The equilibrium state indicates that the interface is saturated and no more change would take place over time while the dynamic surface tension indicates how fast or slow the surface active molecules move to the interface. The pendant drop method (droplet-in-air) with appropriate precaution for evaporation and captive bubble (bubblein-solution) method are commonly used for studying the dynamic adsorption process (Miller, Sedev, Schano, Ng, \& Neumann, 1993). In this study, the captive bubble method was used where possible and pendant drop method was used where the former was not stable for the solutions, especially with surfactants. A small amount of test solution was kept at the bottom of the cuvette while using the pendant drop method in order to minimize the effect due to evaporation.

The instrument was calibrated with MilliQ water and absolute ethanol ensuring that the surface tension of water and ethanol remained in the range of $72.5-73.0 \mathrm{mN} / \mathrm{m}$ and $22.0 \mathrm{mN} / \mathrm{m}$, respectively. A droplet with a surface volume of $10 \mathrm{~mm}^{3}$ was generated at the tip of the needle for MilliQ water, ethanol and the test solutions. The temperature of the test chamber was kept constant at $20 \pm 0.5^{\circ} \mathrm{C}$ by circulating thermostated water from an external bath. Surface tension values were recorded for $50 \mathrm{~s}$. All experiments were carried out in triplicate.

\subsubsection{Solubility}

Solubilities of NaCas and PPI were determined by a modification method of Rangel, Domont, Pedrosa, and Ferreira (2003). Protein was diluted in MilliQ water at a concentration of $0.5 \mathrm{mg} / \mathrm{ml}$ in a final volume of $5 \mathrm{ml}$. Then $\mathrm{pH}$ of the solutions was carefully adjusted to $6.5,7.4$ and 8.0 by adding $0.1 \mathrm{~N} \mathrm{HCl}$ or $0.1 \mathrm{~N} \mathrm{NaOH}$. 
The $\mathrm{pH}$ of two samples was unadjusted and taken as natural $\mathrm{pH}$. After 60 min of stirring (with a magnetic stirrer at room temperature), the $\mathrm{pH}$ of the solutions was again measured and samples were subjected to centrifugation (Rotofix 32A) at $4000 \mathrm{rpm}$ at room temperature for $15 \mathrm{~min}$. The protein concentration of the supernatants was determined according to Lowry, Rosebrough, Farr, and Randall (1951) method and expressed as a percentage of the initial protein concentration.

\subsubsection{Observation of surface stickiness}

Surface stickiness of sucrose-NaCas (99.5:0.5) and sucrose-PPI (99:1) solutions was observed using a custom built in situ stickiness measuring instrument. This device works on the principle of tack, which mimics the feel when one touches a droplet surface. The working principle and the test protocols are given elsewhere (Adhikari, Howes, Bhandari, \& Truong, 2003). The test procedure is briefly given below. The experiment was carried out at $65^{\circ} \mathrm{C}$ as this is the outlet temperature in our spray-drying trials. The velocity and the relative humidity of the drying air were $0.5 \mathrm{~m} / \mathrm{s}$ and $5.5 \%$, respectively. The test time was varied between 1 and $2.5 \mathrm{~h}$. The stainless steel probe was driven downwards until it made a good contact with the droplet (initial droplet volume $50 \mu \mathrm{l}$ ) surface. The contact and withdrawal speeds were maintained at $50 \mathrm{~mm} / \mathrm{min}$ in all experiments. Once the contact was established, the probe was withdrawn. Digital images during approach, contact and withdrawal were recorded.

\section{Results \& discussion}

\subsection{DST and extent of protein and surfactant migration to the surface}

The DST values of sucrose-NaCas with and without Tween-80 and sucrose-PPI with and without Tween-80 are presented in Fig. 1(a) and (b), respectively. DST of sugar, NaCas, PPI, Tween-80 and SSL are also provided for comparison. DST values of $25 \%$ sucrose solution $(73.61 \pm 0.28 \mathrm{mN} / \mathrm{m})$ did not change over time as expected since sucrose is not surface active (Figs. 1 and 2). The DST values of $0.13 \%$ NaCas and $0.26 \%$ PPI ranged from $54.23 \pm 1.13 \mathrm{mN} / \mathrm{m}$ to $51.98 \pm 0.46 \mathrm{mN} / \mathrm{m}$ and from $57.67 \pm 4.24 \mathrm{mN} / \mathrm{m}$ to $54.01 \pm 0.44 \mathrm{mN} / \mathrm{m}$, respectively during $50 \mathrm{~s}$ (Figs. 1 and 2). When $0.13 \%$ NaCas was added to sucrose solution the DST value reduced to $52.73 \pm 0.31 \mathrm{mN} / \mathrm{m}$ at $50 \mathrm{~s}$. This DST value is similar to that of $0.13 \%$ NaCas confirming that at this protein concentration, NaCas manages to migrate to the air-water interface almost instantly. This observation indicates that the protein preferentially migrates to the air-water interface reasonably fast. When $0.26 \%$ PPI was added to sucrose solution the dynamic surface tension value reduced to $52.14 \pm 0.78 \mathrm{mN} / \mathrm{m}$ at $50 \mathrm{~s}$ which was comparable to that of sucrose-NaCas. Although comparable DST values were obtained for sucrose-NaCas and sucrose-PPI, it is worth noting that the amount of PPI added was twice that of NaCas. The reason for a higher amount of PPI required to achieve the same extent of migration to air-water interface can be attributed to the structural and compositional differences between these two proteins such as solubility (Fig. 4). The low solubility of the PPI means that as the drying progresses less active protein will be available to migrate to the droplet-air interface which can lower its efficacy compared to NaCas whose solubility within the $\mathrm{pH}$ range is considerably high (Fig. 4). Furthermore, NaCas has a disordered structure with high flexibility while PPI is a globular protein with less flexibility (Subirade et al., 1992).

Addition of $0.01 \%$ Tween- 80 into both sucrose-NaCas and sucrose-PPI solutions further reduced the surface tension values
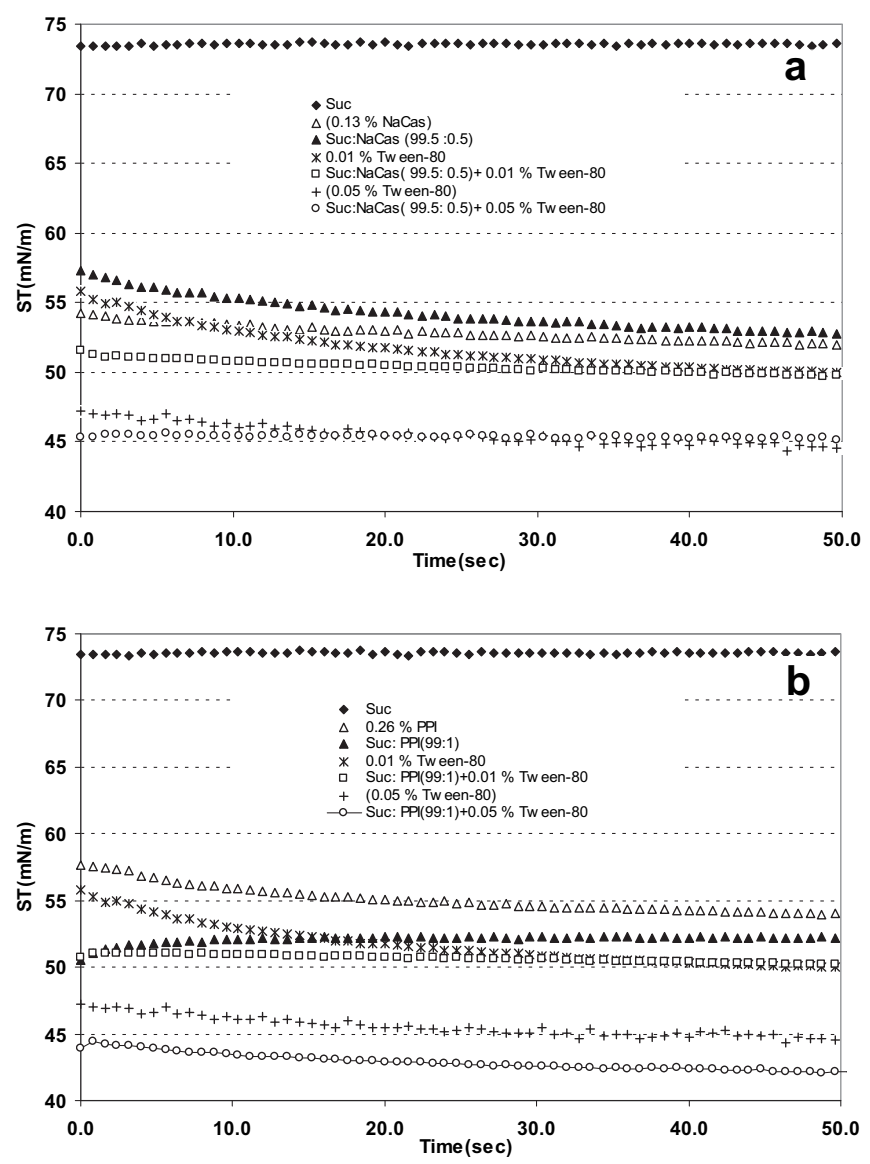

Fig. 1. (a) Dynamic surface tension $(\mathrm{mN} / \mathrm{m})$ for solution of sucrose-NaCas in the absence and presence of Tween- 80 and (b) dynamic surface tension $(\mathrm{mN} / \mathrm{m})$ for solution of sucrose-PPI in the absence and presence of Tween- 80 .

indicating that a certain fraction of protein molecules was displaced from the surface. We will discuss this aspect later in the text using surface elemental analysis of the resultant powders. It was interesting to note that when the Tween-80 concentration was increased from $0.01 \%$ to $0.05 \%$ in the sucrose-NaCas solution, the DST values decreased to their minimum almost immediately $(0.8 \mathrm{~s})$ (Fig. 1(a)). This outcome suggests that Tween-80 had displaced almost all the proteins from the surface, which is indicated by surface elemental analysis results (Section 3.4.). In the case of sucrose-PPI-Tween-80 (0.05\%) solution, it took a much longer time (about $40 \mathrm{~s}$ ) for the DST values to reach the minimum indicating that the conformational rearrangements for surface coverage and loop and tail formation are easier when protein molecules are flexible like in the case of NaCas (Le Meste et al., 1990).

Addition of $0.01 \%$ SSL into sucrose-NaCas solution reduced the DST values from $44.01 \pm 3.34 \mathrm{mN} / \mathrm{m}$ to $43.36 \pm 0.85 \mathrm{mN} / \mathrm{m}$ (Fig. 2(a)) whereas the values were found to be in the range of $40.44 \pm 0.69 \mathrm{mN} / \mathrm{m}$ and $40.37 \pm 0.79 \mathrm{mN} / \mathrm{m}$ in sucrose-NaCas with $0.05 \%$ SSL. It is worth noting that immediately after the start of the experiment the DST values reached their minimum irrespective of the SSL concentration $(0.01 \%$ or $0.05 \%)$ in sucrose-NaCas solutions. The DST values were reduced from $49.02 \pm 1.38 \mathrm{mN} / \mathrm{m}$ to $47.71 \pm 0.41 \mathrm{mN} / \mathrm{m}$ and from $49.51 \pm 2.74 \mathrm{mN} / \mathrm{m}$ to $40.10 \pm 0.26 \mathrm{mN} / \mathrm{m}$ with the addition of $0.01 \%$ SSL and $0.05 \%$ SSL, respectively into sucrose-PPI solution (Fig. 2(b)). It is interesting to note that the DST values of solutions with Tween-80 were higher than those with SSL in the case of sucrose-NaCas solution. This suggests that if the lowered DST 

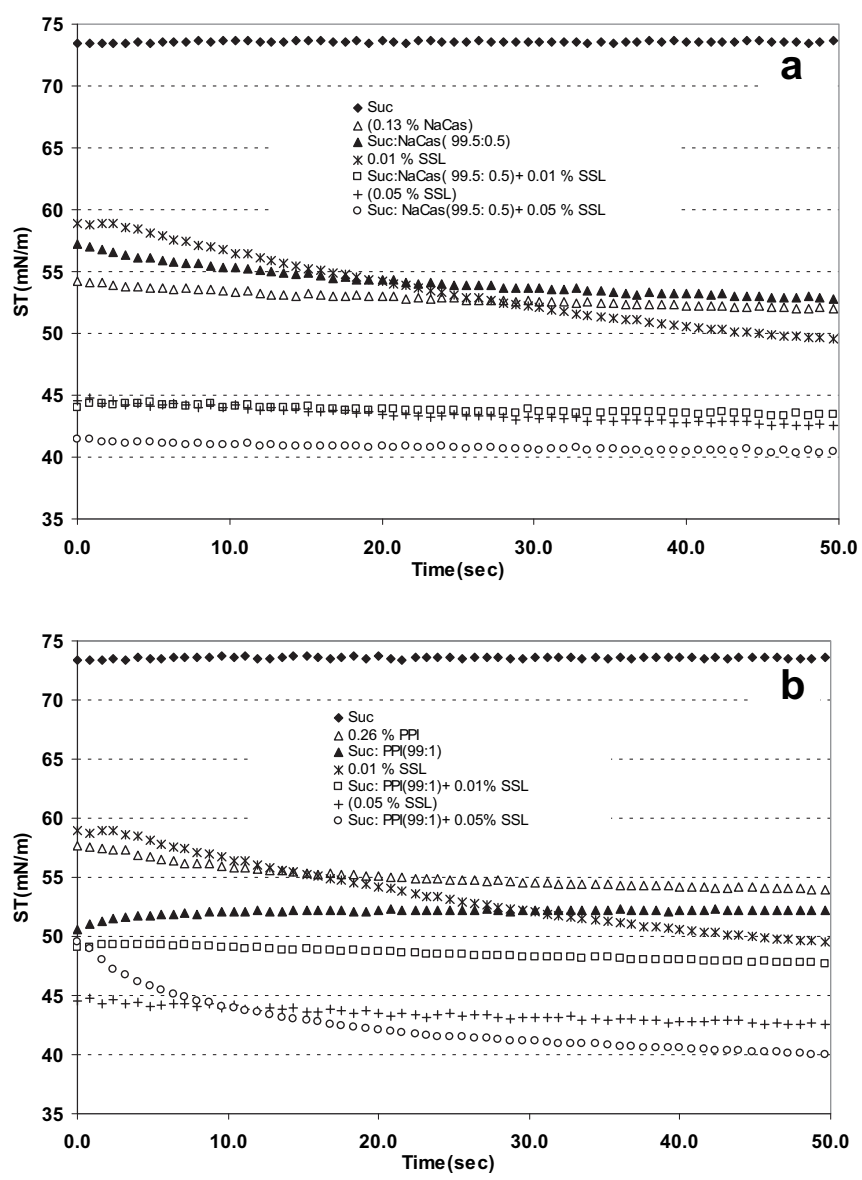

Fig. 2. (a) Dynamic surface tension $(\mathrm{mN} / \mathrm{m})$ for solution of sucrose-NaCas in the absence and presence of SSL and (b) dynamic surface tension $(\mathrm{mN} / \mathrm{m})$ for solution of sucrose-PPI in the absence and presence of SSL.

values are to directly correlate to the surface occupation by LMS or the displacement of the proteins from the droplet surface, the SSL should have occupied more surface and thereby displacing more protein from the surface compared to that of Tween-80. However, it is not the case when powder recoveries are considered. This suggests that the surface activity alone cannot explain the powder recovery. It was suggested that it is the kinetics of surfactant-protein-surface interactions and the mechanism with which the surfactants displace the proteins from the airwater interface that are responsible for the different powder recoveries (Adhikari, Howes, Wood, et al., 2009; Gunning et al., 2004).

\subsection{Powder recovery}

The recovery of sucrose-NaCas and sucrose-PPI powders with or without LMS was determined (Fig. 3(a) and (b)). A zero powder recovery indicates that all the sucrose solids in the feed were lost as wall deposits. When the dryer was cooled down, the deposited sucrose crystallised and part of it could be recovered as wall deposits but not as amorphous powder. This result agrees with the previous studies of spraying of sucrose under similar conditions (Truong, Bhandari, \& Howes, 2005b). When 0.5\% of NaCas was added to the sucrose solution the total recovery rose to $82.0 \pm 1.4 \%$ while the cyclone recovery rose to $59.0 \pm 1.7 \%$ (Fig. 3(a)). A total powder recovery of $50 \%$ is taken to be the benchmark for a successful spray drying (Bhandari et al., 1997). The greatly
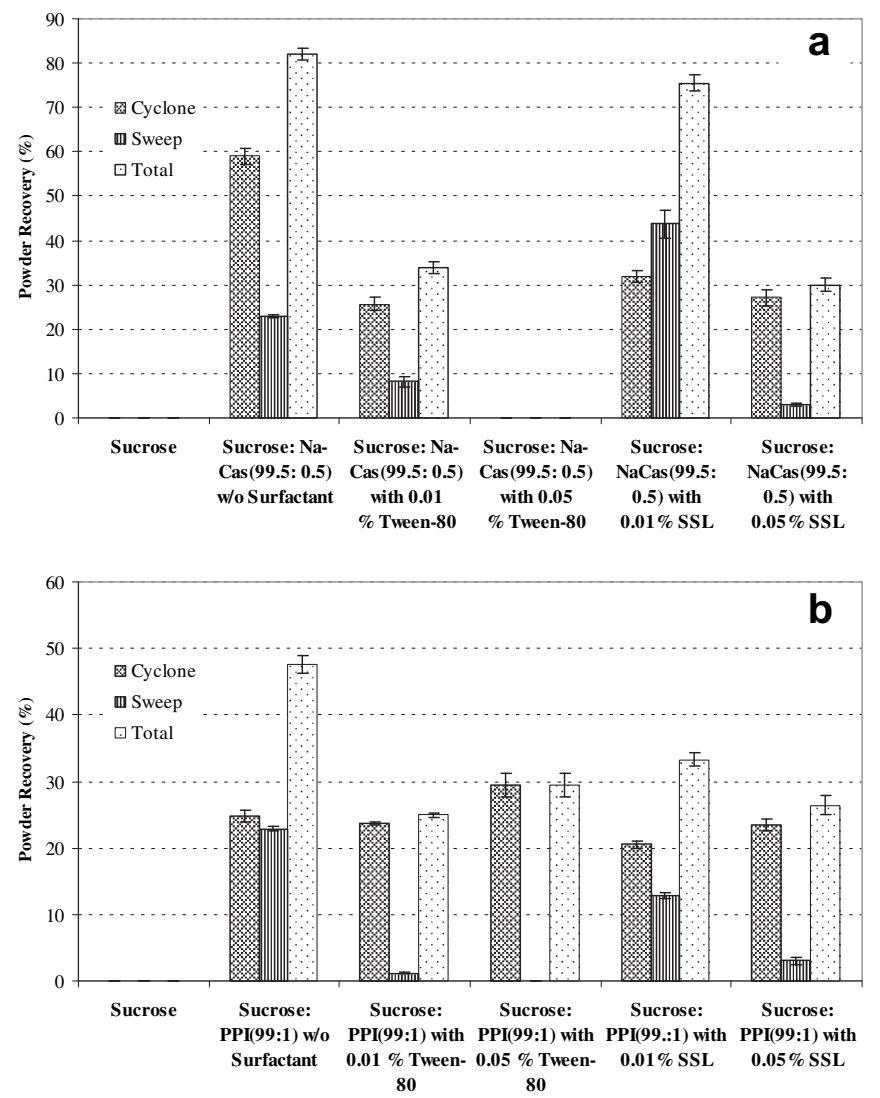

Fig. 3. (a) Recovery of sucrose-NaCas powders in the absence and presence of LMS in spray-drying trials and (b) recovery of sucrose-PPI powders in the absence and presence of LMS in spray-drying trials.

enhanced powder recovery indicates that proteins preferentially migrate to the air-water interface of sugar solutions and form a protein-rich film. This film is converted into a glassy skin when it is subjected into hot and dry air. The resultant skin is capable of overcoming the coalescence of droplets as well as sticky interactions of the particles at the drying chamber of the spray-dryer (Adhikari et al., 2007).

However, when $1 \%$ sucrose was replaced by PPI (Fig. 3(b)) the total recovery rose only to $47.7 \pm 1.3 \%$, which is below the benchmark value reported for successful spray-drying trials. This result indicates that the PPI is not as effective as NaCas as a smart drying aid due to its low solubility (Fig. 4). This protein can still be much more effective than maltodextrin as a drying aid as $40-60 \%$ of the

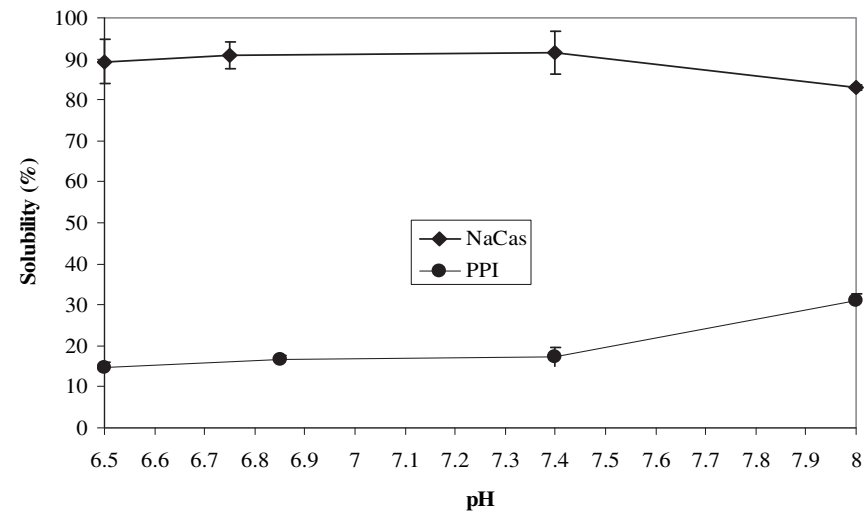

Fig. 4. pH dependence of the solubilities of NaCas and PPI. 
latter is required to achieve a similar level of powder recovery of sucrose solutions (Truong, Bhandari, \& Howes, 2005a). It can also be seen from Fig. 3(a) that addition of $0.01 \%$ Tween- 80 into sucrose-NaCas solution has led to a sharp reduction in total powder recovery. Addition of $0.01 \%$ Tween- 80 into sucrose-PPI solution reduced the total powder recovery to almost half $(24.9 \pm 0.4 \%)$ compared to that of sucrose-PPI solution. When the concentration of the Tween- 80 was increased from $0.01 \%$ to $0.05 \%$, no powder was recovered in the case of sucrose-NaCas solutions. The total recovery was more or less the same for sucrosePPI-Tween-80 (0.01\%) and sucrose-PPI-Tween-80 (0.05\%) powders. Even the little amount of powder produced with Tween80 was not amorphous (Fig. 5(a) and (b)). In the case of SSL, the total recovery was $75.5 \pm 1.8 \%$ for sucrose-NaCas powders with $0.01 \%$ SSL and it dropped to $30.1 \pm 1.4 \%$ for powders with $0.05 \%$ SSL. The reason for the drop in total powder recovery is due to the fact that when the SSL concentration is increased, more of SSL occupies the surface thereby pushing the proteins to the bulk. The total recoveries of powders of sucrose-PPI with $0.01 \%$ SSL and $0.05 \%$ SSL were $33.3 \pm 1.0 \%$ and $26.4 \pm 1.4 \%$, respectively. All these results demonstrate that the powder recovery depends on the type of protein, the type of surfactant as well as on the surfactant concentration. X-ray diffraction patterns confirmed that the powders with $0.01 \%$ SSL were amorphous while they were crystalline when they were with $0.05 \%$ SSL (Fig. 5(a) and (b)). The reason for this change in phase (amorphous to crystalline) can be attributed to the coalescence of
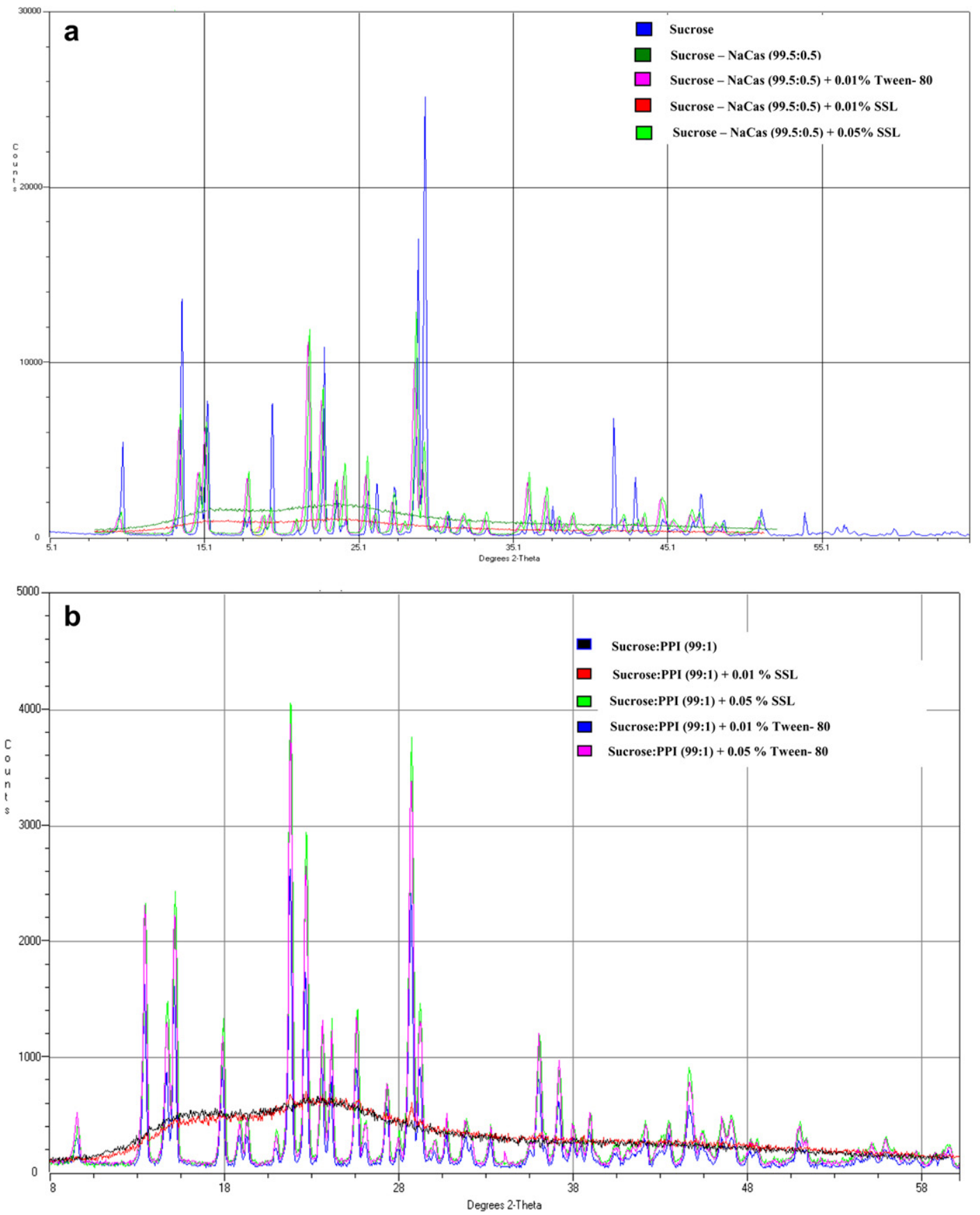

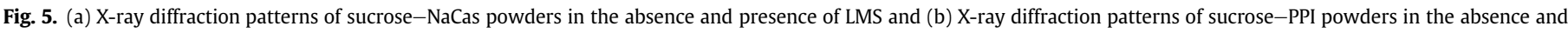
presence of LMS. 
a

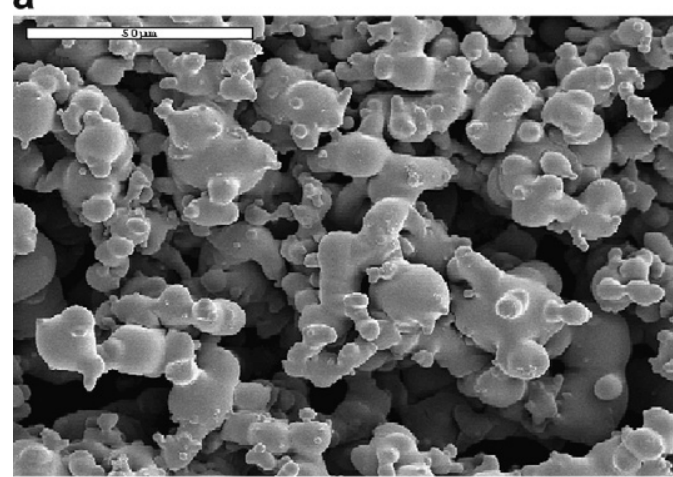

c

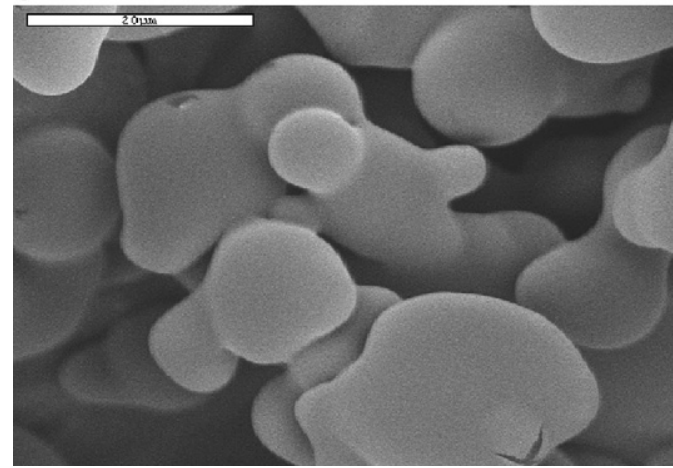

b

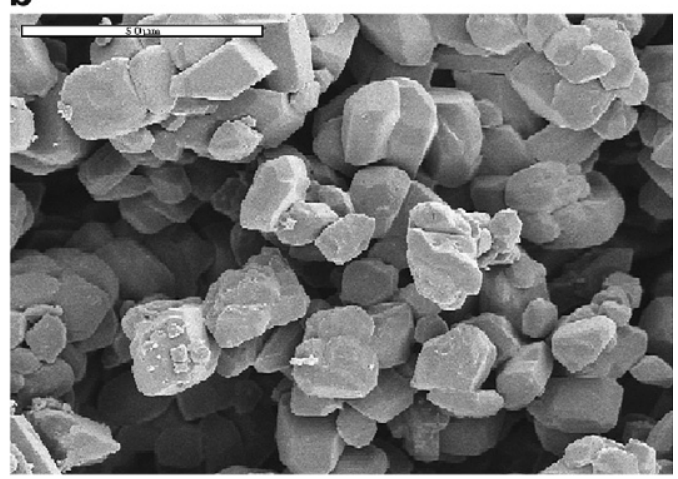

d

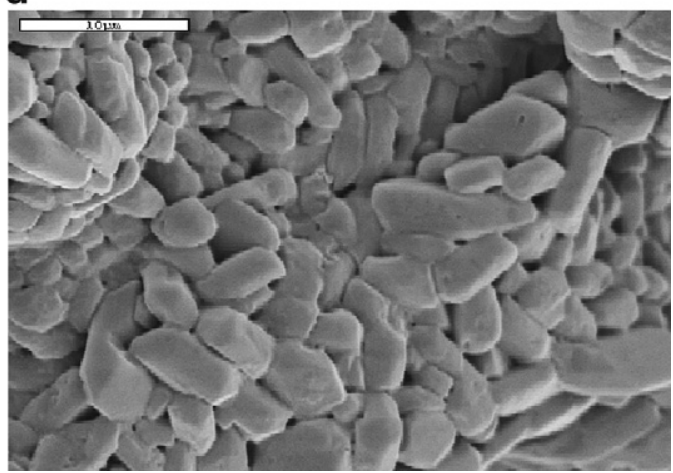

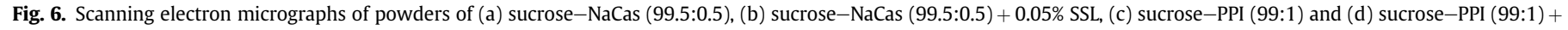
$0.05 \%$ SSL.

multiple droplets into agglomerated powder particles. Although these agglomerated powder particles are not totally fused, however, due to their large size the evaporation slows down considerably. This slow evaporation allows the sucrose molecules to crystallize. These arguments are supported from the existence of multiple discrete crystals (more than 10) in the agglomerates (Fig. 6 (b) and (d)) and exceptionally large particle size (up to 14 times, Table 1 ) in powders containing $0.05 \%$ SSL compared to the powders containing $0.01 \%$ SSL. Total recovery of sucrose-NaCas-SSL $(0.01 \%)$ powder is similar to that of sucrose-NaCas powder indicating that the addition of $0.01 \%$ SSL hasn't affected the protein surface composition and hence the powder recovery. The recovery of sucrose-PPI-SSL (0.01\%) powder is less than that of sucrose-PPI powder. However, the addition of $0.01 \%$ SSL hasn't affected the protein surface composition as will be shown in Section 3.4.

\subsection{Crystalline/amorphous nature of spray-dried powders}

The moisture content, $a_{w}$ and particle size of powders are summarised in Table 1 . It can be seen from this table that the highest moisture content and $\mathrm{a}_{\mathrm{w}}$ of spray-dried powder are $3.83 \pm 0.1$ and $0.84 \pm 0.00$, respectively. The high value in $\mathrm{a}_{\mathrm{w}}$ indicates the presence of a high proportion of free water and that the powder is crystallised. The $\mathrm{a}_{\mathrm{w}}$ values of sucrose-NaCas, sucroseNaCas-SSL (0.01\%), sucrose-PPI and sucrose-PPI-SSL $(0.01 \%)$ are $0.24 \pm 0.01,0.28 \pm 0.01,0.17 \pm 0.01$ and $0.23 \pm 0.00$, respectively. These values are within the range of $\mathrm{a}_{\mathrm{w}}$ values $(\approx 0.2)$ of industrially spray-dried powders (Adhikari, Howes, Bhandari, et al., 2009). One of the characteristics of spray-dried products is the low moisture content which is less than 5\% (Masters, 1991). The moisture content of all the powder samples is well within the range.

Table 1

Physical parameters of sucrose-protein powders with and without LMS

\begin{tabular}{|c|c|c|c|}
\hline \multirow[t]{2}{*}{ Sample } & \multicolumn{3}{|l|}{ Parameters } \\
\hline & $\mathrm{a}_{\mathrm{w}}\left(24.5 \pm 0.5^{\circ} \mathrm{C}\right)$ & Moisture (\%) wb & $\begin{array}{l}\text { Particle size d } \\
{[\mathrm{v}, 0.5](\mu \mathrm{m})}\end{array}$ \\
\hline Sucrose:NaCas (99.5:0.5) & $0.24 \pm 0.01$ & $3.19 \pm 0.1$ & $23.60 \pm 0.25$ \\
\hline Sucrose:NaCas $(99.5: 0.5)+0.01 \%$ Tween-80 & $0.83 \pm 0.01$ & $1.33 \pm 0.0$ & $69.03 \pm 1.20$ \\
\hline Sucrose:NaCas $(99.5: 0.5)+0.01 \%$ SSL & $0.28 \pm 0.01$ & $3.19 \pm 0.1$ & $28.43 \pm 0.01$ \\
\hline Sucrose:NaCas $(99.5: 0.5)+0.05 \%$ SSL & $0.83 \pm 0.02$ & $3.83 \pm 0.1$ & $51.05 \pm 0.73$ \\
\hline Sucrose:PPI (99:1) & $0.17 \pm 0.01$ & $2.61 \pm 0.02$ & $17.16 \pm 0.23$ \\
\hline Sucrose:PPI (99:1) + 0.01\% Tween-80 & $0.84 \pm 0.00$ & $3.72 \pm 0.05$ & $550.07 \pm 46.69$ \\
\hline Sucrose:PPI (99:1) + 0.05\% Tween-80 & $0.73 \pm 0.00$ & $0.36 \pm 0.03$ & $47.00 \pm 1.03$ \\
\hline Sucrose:PPI (99:1) + 0.01\% SSL & $0.23 \pm 0.00$ & $3.54 \pm 0.02$ & $41.48 \pm 0.34$ \\
\hline Sucrose:PPI $(99: 1)+0.05 \%$ SSL & $0.83 \pm 0.00$ & $3.52 \pm 0.02$ & $609.8 \pm 8.80$ \\
\hline Sucrose (commercial) & $0.38 \pm 0.01$ & $0.0 \pm 0.0$ & $885.65 \pm 15.83$ \\
\hline NaCas (commercial) & $0.32 \pm 0.01$ & $5.0 \pm 0.0$ & $86.66 \pm 3.52$ \\
\hline PPI (commercial) & $0.32 \pm 0.00$ & $3.95 \pm 0.04$ & $30.14 \pm 0.49$ \\
\hline SSL (commercial) & $0.36 \pm 0.01$ & $3.7 \pm 0.2$ & $214.48 \pm 7.69$ \\
\hline
\end{tabular}


It can be seen from X-ray diffractograms in Fig. 5(a) and (b) that the powders of sucrose-NaCas-Tween-80 (0.01\%), sucroseNaCas-SSL (0.05\%), sucrose-PPI-Tween-80 (0.01\%), sucrosePPI-Tween-80 (0.05\%) and sucrose-PPI-SSL (0.05\%) were crystalline while sucrose-NaCas, sucrose-NaCas-SSL (0.01\%) and sucrose-PPI-SSL $(0.01 \%)$ were amorphous. The scanning electron micrographs showed that the sucrose-NaCas (99.5:0.5) and sucrose-PPI (99:1) particles are mostly spherical (Fig. 6(a) and (c)) whereas the sucrose-NaCas-SSL (0.05\%) and sucrosePPI-SSL (0.05\%) particles are hexagonal (Fig. 6(b) and (d)). The morphology of these particles apparently gives a good indication of the amorphous and crystalline nature of the powders, spherical particles being amorphous in nature and hexagonal being crystalline (Ando, Ito, Ozeki, Nakayama, \& Nabeshima, 2007; Mantovani, 1991).

The mean particle size of sucrose-NaCas is $23.60 \pm 0.25 \mu \mathrm{m}$ and it is $28.43 \pm 0.01 \mu \mathrm{m}$ for sucrose-NaCas with $0.01 \%$ SSL. These results reveal that there is no major difference in mean particle size of both sucrose-NaCas and sucrose-NaCas with $0.01 \%$ SSL. This leads to somewhat comparable powder yields of these two formulations. However, the mean particle size of sucrose-PPI is less than that of the sucrose-PPI-SSL $(0.01 \%)$ indicating that the greater powder recovery in the case of the former is not due to better collection of bigger particles. Sucrose-NaCas-Tween-80 $(0.01 \%)$ and sucrose-NaCas-SSL $(0.05 \%)$ showed higher mean particle size compared to that of sucrose-NaCas and sucroseNaCas-SSL (0.01\%). The mean particle size of sucroseNaCas-Tween-80 (0.01\%) was $69.03 \pm 1.20 \mu \mathrm{m}$ whereas it was $51.05 \pm 0.73 \mu \mathrm{m}$ in the case of sucrose-NaCas-SSL (0.05\%). Addition of just $0.01 \%$ Tween-80 into sucrose-PPI solution has increased the mean particle size of sucrose-PPI-Tween-80 (0.01\%) powder to seven times more than that of the sucroseNaCas-Tween-80 (0.01\%). This increment in particle size may be due to two reasons. Firstly, two or more sticky droplets might have coalesced immediately after atomisation and resulted in a larger particle upon subsequent drying. Secondly, this can also be due to agglomeration of crystalline particles. Although we have sonicated the powder samples during particle size measurement, it may not be fully possible to break all the agglomerates. With the addition of $0.05 \%$ Tween-80 the particle size reduced to $47.00 \pm 1.03 \mu \mathrm{m}$. However, as its $\mathrm{a}_{\mathrm{w}}$ was high, it was crystalline. The mean particle size of sucrose-PPI-SSL $(0.05 \%)$ powder was higher than that of sucrose-PPI-SSL $(0.01 \%)$ indicating that the former was agglomerated. Excessively high mean particle size indicates that the powders are agglomerated.

\subsection{The protein surface coverage and its implication on powder recovery}

The elemental compositions of carbon, oxygen and nitrogen at the surface of the sucrose-NaCas and sucrose-PPI powders with or without LMS are presented in Table 2. The elemental compositions of sucrose, NaCas, PPI and SSL are given as a reference. It can be seen that the error in measurements in pure samples is within $5 \%$ of the theoretical value in most of the cases (Table 2). In the absence of LMS, $52.0 \%$ of the surface of sucrose-NaCas particles is covered by the protein (sodium caseinate) although the feed solution contained only $0.13 \%$ protein (Table 2 ). It is interesting to note that the initial bulk composition of $0.13 \%$ NaCas was able to cover $52.0 \%$ (on mass basis) of the surface of sucrose-NaCas particles. This resulted in $82.0 \%$ powder recovery (Fig. 3(a)). This level of surface coverage is attributed to preferential migration and rapid kinetics of proteins to the air-water interface. It is worth mentioning here that no sucrose powder was recovered in the absence of the sodium caseinate or PPI.

Although $0.26 \%$ PPI was able to cover $89.0 \%$ of the surface of sucrose-PPI particles, it could not produce a powder recovery comparable to that of sucrose-NaCas. The low powder recovery of sucrose-PPI may be due to the poor-skin-forming property of PPI (Fig. 7(b)). To further explore the difference in skin-forming nature of NaCas and PPI, we conducted surface tackiness tests under identical test conditions $\left(65^{\circ} \mathrm{C}\right.$ temperature, $5.5 \% \mathrm{RH}, 0.5 \mathrm{~m} / \mathrm{s}$ air velocity and $50 \mathrm{~mm} / \mathrm{min}$ probe withdrawal speed) using solutions of sucroseNaCas (99.5:0.5) and sucrose-PPI (99:1). The mode of failure at probe-sucrose:NaCas (99.5:0.5) droplet interface at non sticky state and the mode of failure at probe-sucrose:PPI (99:1) droplet interface at sticky state at $2 \mathrm{~h}$ are presented in Fig. 7(a) and (b), respectively. It can be seen that no material-probe bonding has taken place at probe-sucrose:NaCas interface due to skin formation (Fig. 7(a)). However, in the case of sucrose-PPI due to non-skin formation, the breakage has taken place within the drop (sucrose-PPI) itself and upon separation the probe surface has remained fully covered with the residual material (Fig. 7(b)). Further, it has been reported that the film formation at the interface depends on the tertiary structure of the protein (Le Meste et al., 1990). NaCas has a disordered structure with high flexibility while PPI is a globular protein with less flexibility (Subirade et al., 1992).

The powder recoveries of both sucrose-NaCas and sucroseNaCas with $0.01 \%$ SSL are comparable to each other (Fig. 3(a)) indicating that addition of $0.01 \%$ SSL hasn't affected the surface coverage by proteins very much. In the case of PPI, the addition of

Table 2

Surface composition of reference samples and spray-dried powders of sucrose-protein with or without Tween-80 and SSL.

\begin{tabular}{|c|c|c|c|c|c|c|c|c|c|c|}
\hline \multirow[t]{2}{*}{ Sample } & \multicolumn{3}{|l|}{ Carbon (\%) } & \multicolumn{3}{|l|}{ Oxygen (\%) } & \multicolumn{3}{|l|}{ Nitrogen (\%) } & \multirow{2}{*}{$\begin{array}{l}\text { Protein on } \\
\text { surface (\%) }\end{array}$} \\
\hline & Ex (\%) & Th (\%) & Error (\%) & Ex (\%) & Th (\%) & Error (\%) & Ex (\%) & Th (\%) & Error (\%) & \\
\hline Sucrose & $53.66 \pm 2.37$ & 52.17 & 1.49 & $46.34 \pm 2.37$ & 47.83 & 1.49 & $0.00 \pm 0.00$ & 0.00 & 0.00 & - \\
\hline $\mathrm{NaCas}$ & $72.57 \pm 0.42$ & 65.00 & 7.57 & $13.77 \pm 0.32$ & 19.00 & 5.23 & $12.99 \pm 0.56$ & 16.00 & 3.01 & - \\
\hline PPI & $77.0 \pm 0.012$ & - & & $13.9 \pm 0.00$ & - & & $8.2 \pm 0.002$ & - & & - \\
\hline SSL & $89.77 \pm 0.061$ & 77.42 & 12.35 & $14.99 \pm 0.002$ & 19.35 & 4.36 & $0.00 \pm 0.00$ & 0.00 & 0.00 & - \\
\hline Tween-80 & - & 71.11 & - & - & 28.89 & - & - & 0.00 & - & - \\
\hline NaCas $(99.5: 0.5)$ & $64.01 \pm 0.02$ & - & - & $28.86 \pm 0.15$ & - & - & $6.77 \pm 0.18$ & - & - & $52.1 \pm 0.3$ \\
\hline Sucrose:NaCas $(99.5: 0.5)+0.01 \%$ Tween-80 & $61.39 \pm 0.09$ & - & - & $36.96 \pm 0.01$ & - & - & $1.66 \pm 0.001$ & - & - & $12.8 \pm 0.0$ \\
\hline Sucrose:NaCas $(99.5: 0.5)+0.01 \%$ SSL & $63.38 \pm-0.06$ & - & - & $29.92 \pm-0.03$ & - & - & $6.58 \pm 0.35$ & - & - & $50.1 \pm 0.6$ \\
\hline Sucrose:NaCas (99.5:0.5) + 0.05\% SSL & $78.30 \pm-0.03$ & - & - & $18.30 \pm-0.04$ & - & - & $2.96 \pm 0.17$ & - & - & $22.8 \pm 0.3$ \\
\hline Sucrose:PPI (99:1) & $64.6 \pm 0.000$ & - & - & $28.0 \pm 0.002$ & - & - & $7.3 \pm 0.001$ & - & - & $89.0 \pm 0.003$ \\
\hline Sucrose:PPI (99:1) + 0.01\% Tween-80 & $67.7 \pm 0.000$ & - & - & $30.9 \pm 0.007$ & - & - & $1.4 \pm 0.009$ & - & - & $17.1 \pm 0.016$ \\
\hline Sucrose:PPI (99:1) + 0.05\% Tween-80 & $67.7 \pm 0.000$ & - & - & $31.1 \pm 0.017$ & - & & $1.2 \pm 0.010$ & - & - & $14.6 \pm 0.017$ \\
\hline Sucrose:PPI $(99: 1)+0.01 \%$ SSL & $63.1 \pm 0.002$ & - & - & $30.2 \pm 0.018$ & - & - & $6.7 \pm 0.006$ & - & - & $81.7 \pm 0.026$ \\
\hline Sucrose:PPI (99:1) + 0.05\% SSL & $67.2 \pm 0.001$ & - & - & $30.4 \pm 0.015$ & - & - & $2.0 \pm 0.003$ & - & - & $36.6 \pm 0.019$ \\
\hline
\end{tabular}

Ex - experimental; Th - theoretical. 

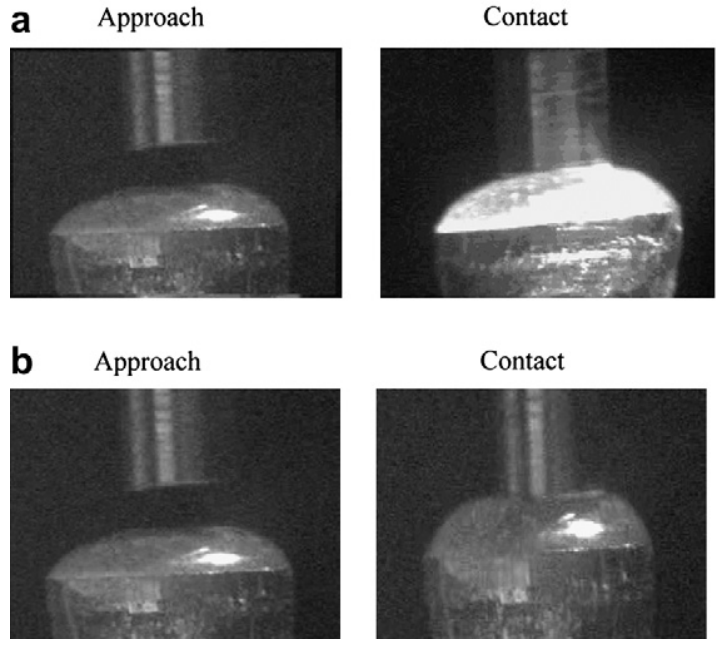

Withdrawal of probe

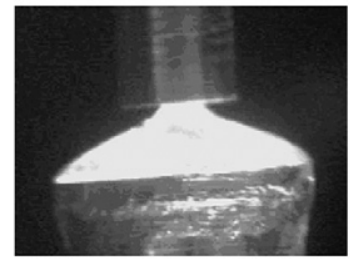

Withdrawal of probe

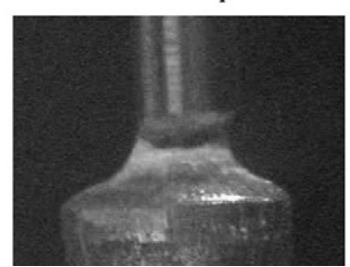

Complete withdrawal of probe

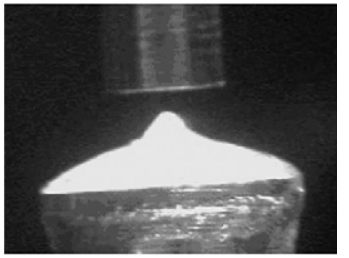

Complete withdrawal of probe

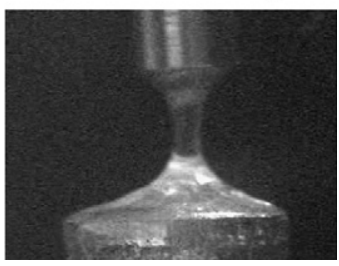

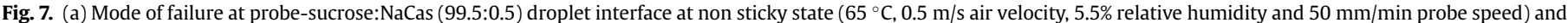
(b) mode of failure at probe-sucrose:PPI (99:1) droplet interface at sticky state $\left(65{ }^{\circ} \mathrm{C}, 0.5 \mathrm{~m} / \mathrm{s}\right.$ air velocity, $5.5 \%$ relative humidity and $50 \mathrm{~mm} / \mathrm{min}$ probe speed).

$0.01 \%$ SSL reduced the surface protein coverage from $89.0 \%$ to $81.7 \%$ indicating that $7.3 \%$ of protein was displaced from the surface with the addition of $0.01 \%$ SSL (Table 2). This amount of protein displacement reduced the powder recovery of sucrose-PPI-SSL $(0.01 \%)$ by $14.3 \%$. It was observed that with the addition of $0.05 \%$ SSL into sucrose-NaCas, the recovery dropped to $30 \%$ since the surface protein coverage has reduced to less than half $(22.8 \pm 0.3 \%)$ compared to that of sucrose-NaCas powder. This result indicates that the addition of $0.05 \%$ SSL has displaced $29.3 \%$ of proteins from the surface. On the other hand when $0.05 \%$ SSL was added to sucrose-PPI droplet the SSL displaced $52.4 \%$ of protein from the surface. These results show that the displacement of proteins from the surface was greater in powders of sucrose-PPI-SSL $(0.05 \%)$ compared to that of sucrose-NaCas-SSL (0.05\%) (Fig. 3(a) and (b)).

When $0.01 \%$ Tween-80 was added to sucrose-NaCas droplet, the protein surface coverage reduced from $52.0 \%$ to $12.8 \%$. This indicates that $0.01 \%$ Tween- 80 was able to replace $39.3 \%$ of total protein on the droplet surface. At this level of displacement of protein from the surface, the powder recovery dropped from $82.0 \%$ to $33.8 \%$, which is below the benchmark for a successful spraydrying operation (Bhandari et al., 1997). With the addition of $0.05 \%$ Tween-80, no powder was recovered indicating that the protein was displaced/dislodged from the surface to the extent that it was impossible for the residual surface coverage of the protein to overcome the stickiness. In this case since we were unable to recover any powder, the determination of the residual surface coverage of the protein was not possible. It was observed that when $0.01 \%$ and $0.05 \%$ Tween- 80 were added to sucrose-PPI droplets the surface protein coverage dropped to $17.1 \%$ and $14.6 \%$, respectively, indicative of very little powder recoveries in both the cases.

\subsection{Surface glass transition temperature and powder recovery}

The $\mathrm{T}_{\mathrm{g}}$ of multi-component mixtures was calculated using a mass weighted mean rule (Adhikari, Howes, Bhandari, et al., 2009). The multi-component mixture is assumed to be composed of $\mathrm{n}$ individual binary solid-water mixtures, where $\mathrm{n}$ is the number of solid components. The moisture dependence of $T_{g}$ for each binary solid-water mixture is determined using the well known Gordon-Taylor Equation (1) (Gordon \& Taylor, 1952).

$\mathrm{T}_{\mathrm{g}, \text { solid-water }}=\frac{\mathrm{X}_{\mathrm{s}} \mathrm{T}_{\mathrm{g}, \mathrm{s}}+\mathrm{X}_{\mathrm{w}} \mathrm{K}_{\mathrm{s}, \mathrm{w}} \mathrm{T}_{\mathrm{g}, \mathrm{w}}}{\mathrm{X}_{\mathrm{s}}+\mathrm{X}_{\mathrm{w}} \mathrm{K}_{\mathrm{s}, \mathrm{w}}}$
$\mathrm{T}_{\text {g.solid-water }}$ is the glass transition temperature of a solid-water binary mixture, $X_{s}$ and $X_{W}$, respectively, are the mass fractions of solid and water in solution. $T_{g, s}$ is the $T_{g}$ of anhydrous solid, $T_{g, w}$ is the $T_{g}$ of pure water and $K_{s, w}$ is a dimensionless proportionality constant that provides the moisture dependence of $T_{g}$. The $T_{g}$ of the multi-component mixture is calculated as a mass weighted mean on a water free basis (Equations (2) and (3)) assuming that the solids are uniformly mixed in the system.

$$
\begin{aligned}
& \mathrm{T}_{\mathrm{g}, \text { mixture }}=\sum_{\mathrm{i}=1}^{\mathrm{n}} \mathrm{T}_{\mathrm{g}, \mathrm{i}-\mathrm{w}} \mathrm{X}_{\mathrm{i}} \\
& \sum_{\mathrm{i}=1}^{\mathrm{n}} \mathrm{X}_{\mathrm{i}}=1
\end{aligned}
$$

$T_{g, \text { mixture }}$ is the $T_{g}$ of the multi-component mixture including water. $\mathrm{T}_{\mathrm{g}, \mathrm{i} \text {-w }}$ represents the $\mathrm{T}_{\mathrm{g}}$ of binary solid-water mixtures such as sucrose-water, NaCas-water, PPI-water and SSL-water etc. $\mathrm{X}_{\mathrm{i}}$ is the mass fraction of an individual solid component on a water free solid basis. For each binary solid-water mixture, the effect of water has been incorporated through the $\mathrm{T}_{\mathrm{g}}$ relationship. The experimental $T_{g}$ values obtained through both the TMCT and DSC are presented in Table 3. As can be seen from this table that the both these methods give very close experimental $T_{g}$ values. The predicted bulk (experimental) $T_{g}$ and surface $T_{g}$ of spray-dried powders at various moisture contents are presented in Table 3. The predicted $T_{g}$ values agree with the experimental values within $4.6{ }^{\circ} \mathrm{C}$ in the case of sucrose-NaCas powders with or without surfactants. The difference between experimental bulk $T_{g}$ and the predicted bulk $\mathrm{T}_{\mathrm{g}}$ for sucrose-PPI (99:1) powder was $10.2^{\circ} \mathrm{C}$ and was $6.4^{\circ} \mathrm{C}$ in the case of sucrose-PPI-SSL $(0.01 \%)$ powder. It can be seen from Table 3 that the predicted glass transition temperature values of the surface layer is about $30-40{ }^{\circ} \mathrm{C}$ higher than the corresponding glass transition temperature of bulk composition in the case of both sucrose-NaCas and sucrose-PPI powders. It is established that for the powder particles to be sticky the operational temperature has to exceed the glass transition temperature by $20^{\circ} \mathrm{C}$ (Roos \& Karel, 1991). Therefore, the particles have remained within the safe drying region for sucrose-NaCas and sucrose-PPI powders.

It is interesting to note that there was no difference between predicted bulk $T_{g}$ and surface $T_{g}$ for the sucrose-NaCas powders with 
Table 3

Experimental $\mathrm{T}_{\mathrm{g}}$ along with predicted bulk $\mathrm{T}_{\mathrm{g}}$ values and surface $\mathrm{T}_{\mathrm{g}}$ values of spray-dried powders.

\begin{tabular}{|c|c|c|c|c|}
\hline Sample & Moisture (\%) wb & $\mathrm{T}_{\mathrm{g}}(\mathrm{Ex})($ bulk $)\left({ }^{\circ} \mathrm{C}\right)$ & $\begin{array}{l}\mathrm{T}_{\mathrm{g}} \text { (pred) } \\
\text { (bulk) }\left({ }^{\circ} \mathrm{C}\right)\end{array}$ & $\begin{array}{l}\mathrm{T}_{\mathrm{g}} \text { (pred) } \\
\text { (surface layer) } \\
\left({ }^{\circ} \mathrm{C}\right)\end{array}$ \\
\hline Sucrose:NaCas (99.5:0.5) & $3.19 \pm 0.1$ & $54.3 \pm 0.9(58.1 \pm 1.2)$ & 49.7 & 83.2 \\
\hline Sucrose:NaCas $(99.5: 0.5)+0.01 \%$ Tween -80 & $1.33 \pm 0.0$ & Crystalline & - & - \\
\hline Sucrose:NaCas (99.5:0.5) + 0.01\% SSL & $3.19 \pm 0.1$ & $43.9 \pm 2.3(42.4 \pm 1.3)$ & 39.7 & 40.7 \\
\hline Sucrose:NaCas $(99.5: 0.5)+0.05 \% \mathrm{SSL}$ & $3.83 \pm 0.1$ & Crystalline & - & - \\
\hline Sucrose:PPI (99:1) & $2.61 \pm 0.02$ & $54.2 \pm 1.5(53.2 \pm 1.2)$ & 44.0 & 78.9 \\
\hline Sucrose:PPI (99:1) + 0.01\% Tween-80 & $3.72 \pm 0.05$ & Crystalline & - & - \\
\hline Sucrose:PPI $(99: 1)+0.05 \%$ Tween-80 & $0.36 \pm 0.03$ & Crystalline & - & - \\
\hline Sucrose:PPI (99:1) + 0.01\% SSL & $3.54 \pm 0.02$ & $43.7 \pm 1.1(45.6 \pm 1.3)$ & 37.3 & 68.6 \\
\hline Sucrose:PPI (99:1) + 0.05\% SSL & $3.52 \pm 0.02$ & Crystalline & - & - \\
\hline
\end{tabular}

Ex - experimental; pred - predicted.

Bulk $\mathrm{T}_{\mathrm{g}}$ values in parentheses were obtained from DSC.

SSL. It strongly supports the fact that the propensity of NaCas to preferentially occupy the surface is negated by the presence of LMS. It is proven that the kinetics of LMS such as SSL and Tween-80 to move to the surface is much greater than that of the protein due to the small size of the former. It can also be seen that both the SSL and Tween-80 saturate the surface layer instantly. It is also interesting to note that at the prevailing concentration level of protein in both sucrose-NaCas and sucrose-PPI powders, the protein is unable to raise the bulk $T_{g}$ of these powder samples. The experimental bulk $\mathrm{T}_{\mathrm{g}}$ values of sucroseNaCas-SSL (0.01\%) and sucrose-PPI-SSL (0.01\%) were $43.9 \pm 2.3^{\circ} \mathrm{C}$ and $43.7 \pm 1.1^{\circ} \mathrm{C}$, respectively. Addition of $0.01 \%$ SSL into both sucrose-NaCas and sucrose-PPI solutions has reduced the bulk $\mathrm{T}_{\mathrm{g}}$ of powders indicating that the low $\mathrm{T}_{\mathrm{g}}$ of SSL is the reason for the reduction in bulk $\mathrm{T}_{\mathrm{g}}$ of such powders.

\section{Conclusion}

More than $80 \%$ of amorphous sucrose powder was produced through spray drying with the addition of just $0.13 \%$ of sodium caseinate (initial bulk concentration). This is an indication that NaCas can act as a very effective drying aid. However, even with a higher amount of initial PPI concentration (0.26\%), the recovery was less than $50 \%$ which indicates that PPI is not as effective as NaCas as a drying aid. This can be attributed to its poor film-forming property. SSL at concentrations of $0.01 \%$ and $0.05 \%$ displaced $2.0 \%$ and $29.3 \%$ of proteins from the droplet surface of sucrose-NaCas-SSL, respectively. This led to a substantial reduction in total powder recovery from $75.5 \pm 1.8 \%$ to $30.1 \pm 1.4 \%$. The displacement of protein from the surface was higher with the addition of SSL into sucrose-PPI solution. However, the recovery of powder was not much affected as the reduction in powder recovery was only $6.9 \%$ when the SSL concentration varied $0.01-0.05 \%$. Tween-80 was capable of displacing a substantial amount or all the proteins (NaCas) from the droplet surface leading to no powder recovery at its $0.05 \%$ concentration. This surfactant displaced a substantial amount of proteins (NaCas) even when it was used at a trace amount $(0.01 \%)$, yielding a very little powder recovery $(33.8 \pm 1.4 \%)$. In the case of sucrose-PPI powders, the behaviour of Tween- 80 was no different from that of SSL with regard to the powder recovery when the Tween- 80 concentration was increased from $0.01 \%$ to $0.05 \%$. On the whole the powder recovery of sucrose was greatly influenced by the protein type, LMS type and their concentration level. The protein displacement behaviour of surfactants is very useful in controlling the amount of proteins at the surface of a spray-dried powder.

\section{Acknowledgement}

The authors wish to acknowledge Mr. Bruce Armstrong (University of Ballarat), Mr. Stafford McKnight (University of
Ballarat), Dr. Thomas Gengenbach (CSIRO, Clayton, Australia) and Mr. Amir Ghandi (University of Ballarat) for their help in experiments. The authors also wish to thank Mr. Richard Lea for proof reading this article. This work is partially supported by the Australian Research Council's Discovery Grant Scheme (DP0772260).

\section{References}

Adhikari, B., Howes, T., Bhandari, B. R., \& Langrish, T. A. G. (2009). Effect of addition of proteins on the production of amorphous sucrose powder through spray drying. Journal of Food Engineering, 94, 144-153.

Adhikari, B., Howes, T., Bhandari, B. R., \& Truong, V. (2003). In situ characterization of stickiness of sugar-rich foods using a linear actuator driven stickiness testing device. Journal of Food Engineering, 58, 11-22.

Adhikari, B., Howes, T., Shrestha, A. K., \& Bhandari, B. R. (2007). Development of stickiness of whey protein isolate and lactose droplets during convective drying. Chemical Engineering and Processing, 46, 420-428.

Adhikari, B., Howes, T., Wood, B. J., \& Bhandari, B. R. (2009). The effect of low molecular weight surfactants and proteins on surface stickiness of sucrose during powder formation through spray drying. Journal of Food Engineering, 94 135-143.

Ando, M., Ito, R., Ozeki, Y., Nakayama, Y., \& Nabeshima, T. (2007). Evaluation of a novel sugar coating method for moisture protective tablets. International Journal of Pharmaceutics, 336(2), 319-328.

Bhandari, B. R., Datta, N., \& Howes, T. (1997). Problems associated with spray drying of sugar-rich foods. Drying Technology, 15(2), 671-684.

Boonyai, P., Bhandari, B., \& Howes, T. (2004). Stickiness measurement techniques for food powders: a review. Powder Technology, 145, 34-46.

Downton, G. E., Flores-Luna, J. L., \& King, C. J. (1982). Mechanisms of stickiness in hygroscopic, amorphous powders. Industrial \& Engineering Chemistry Fundamentals, 21(4), 447-451.

Fäldt, P., Bergenståhl, B., \& Carlsson, G. (1993). The surface coverage of fat on food powders analyzed by ESCA (electron spectroscopy for chemical analysis). Food Structure, 12, 225-234.

Gabas, A. L., Telis, V. R. N., Sobral, P. J. A., \& Telis-Romero, J. (2007). Effect of maltodextrin and arabic gum in water vapor sorption thermodynamic properties of vacuum dried pineapple pulp powder. Journal of Food Engineering, 82(2) $246-252$.

Gordon, M., \& Taylor, J. S. (1952). Ideal copolymers and the second-order transitions of synthetic rubbers. I. Non-crystalline copolymers. Journal of Applied Chemistry, 2, 493-500.

Gunning, P. A., Mackie, A. R., Gunning, A. P., Woodward, N. C., Wilde, P. J., \& Morris, V. J. (2004). Effect of surfactant type on surfactant-protein interactions at the air-water interface. Biomacromolecules, 5(3), 984-991.

Jayasundera, M., Adhikari, B. P., Adhikari, R., \& Aldred, P. (2010). The effect of food grade low molecular weight surfactants and sodium caseinate on spray-drying of sugar-rich foods. Food Biophysics, 5, 128-137.

Kalichevsky, M. T., \& Blanshard, J. M. (1993). The effect of fructose and water on the glass transition of amylopectin. Carbohydrate Polymers, 20(2), 107-113.

Knorr, D. (1998). Technology aspects related to microorganisms in functional foods. Trends in Food Science E Technology, 9, 295-306.

Le Meste, M., Colas, B., Simatos, D., Closs, B., Courthaudon, J. L., \& Lorient, D. (1990). Contribution of protein flexibility to the foam properties of casein. Journal of Food Science, 55(5), 1445-1447.

Lowry, O. H., Rosebrough, N. J., Farr, A. L., \& Randall, R. J. (1951). Protein measurement with the Folin phenol reagent. Journal of Biological Chemistry, 193, 265-275.

Maa, Y. F., \& Hsu, C. C. (1997). Protein denaturation by combined effect of shear and air-liquid interface. Biotechnology and Bioengineering, 54(6), 503-512. 
M. Jayasundera et al. / Food Hydrocolloids 25 (2011) 459-469

469

Mac, Y. F., Nguyen, P. A. T., \& Usu, S. W. (1998). Spray drying of air-liquid interface sensitive recombinant human growth hormone. Journal of Pharmaceutical Sciences, 87(2), 152-159.

Mackle, A. R., Gunning, P. A., Wilde, P. J., \& Morris, V. J. (2000). Competitive displacement of beta-lactoglobulin from the air/water interface by sodium dodecyl sulphate. Langmuir, 16(21), 8176-8181.

Mantovani, G. (1991). Growth and morphology of the sucrose crystal. International Sugar Journal, 93(1106), 23-27.

Masters, K. (1991). Spray drying handbook (Fth ed.). Harlow: Longman.

McClements, D. J. (2005). Food emulsions: Principles, practices and techniques (and ed.). CRC Press.

Miller, R., Seder, R., Schano, K. H., Kg, C., \& Newman, A. W. (1993). Relaxation of adsorption layers at solution/air interfaces using axisymmetric drop-shape analysis. Colloids and Surfaces, 69, 209-216.

O'Brien, R. D. (2009). Fats and oils: Formulating and processing for application (3rd ed.). CRC Press. Taylor and Francis Group.

Pareira, H. V. R., Saraiva, K. P., Carvalho, L. M. J., Andrade, L. R., Pedrosa, C., \& Pierucci, A. P. T. R. (2009). Legumes seeds protein isolates in the production of ascorbic acid microparticles. Food Research International, 42, 115-121.

Pugnaloni, L. A., Dickinson, E., Ettelaie, R., Mackle, A. R., \& Wilde, P. J. (2004) Competitive adsorption of proteins and low molecular-weight surfactants: computer simulation and microscopic imaging. Advances in Colloid and Interface Science, 107, 27-49.

Rangel, A., Domont, G. B., Pedrosa, C., \& Ferreira. (2003). Functional properties of purified vicilins from cowpea (Vina unguiculata) and pea (Pisum sativum) and cowpea protein isolate. Journal of Agricultural and Food Chemistry, 51, 5792-5797.

Righetto, A. M., \& Netts, F. M. (2005). Effect of encapsulating materials on water sorption, glass transition and stability of juice from immature acerola. International Journal of Food Properties, 8(2), 337-346.
Kos, Y., \& Karel, M. (1991). Water and molecular weight effects on glass transitions in amorphous carbohydrates and carbohydrate solutions. Journal of Food Science, 56, 1676-1681.

Rouimi, S., Schorsch, C., Valentini, C., \& Vaslin, S. (2005). Foam stability and interfacial properties of milk protein-surfactant systems. Food Colloids, 19, 467-478.

Sandoval, A. J., Alejandro, M. N., Müller, J., Valle, G. D., \& Lourdin, D. (2009). Glass transition temperatures of a ready to eat breakfast cereal formulation and its main components determined by DSC and DMTA. Carbohydrate Polymers, 76, 528-534.

Shrestha, A. K., Ua-arak, T., Adhikari, B. P., Howes, T., \& Bhandari, B. R. (2007). Glass transition behaviour of spray dried orange juice powder measured by differential scanning calorimetry (DSC) and thermal mechanical compression test (TMCT). International Journal of Food Properties, 10, 661-673.

Subirade, M., Gueguen, J., \& Schwenke, K. D. (1992). Effect of dissociation and conformational changes on the surface behaviour of pea legumin. Journal of Colloid and Interface Science, 152(2), 442-454.

Tonon, R. V., Baroni, A. F., Brabet, C., Gibert, O., Pallet, D., \& Hubinger, M. D. (2009). Water sorption and glass transition temperature of spray dried açai (Euterpe oleracea Mart.) juice. Journal of Food Engineering, 94, 215-221.

Truong, V., Bhandari, B. R., \& Howes, T. (2005a). Optimization of co-current spray drying process for sugar-rich foods. Part I-moisture and glass transition temperature profile during drying. Journal of Food Engineering, 71(1), 55-65.

Truong, V., Bhandari, B. R., \& Howes, T. (2005b). Optimization of co-current spray drying process for sugar-rich foods. Part II-optimization of spray drying process based on glass transition concept. Journal of Food Engineering, 71(1), 66-72.

van Aken, G. A. (2003). Competitive adsorption of protein and surfactants in highly concentrated emulsions: effect of coalescence mechanisms. Colloids and Surfaces A: Physicochemical and Engineering Aspects, 213, 209-219.

Vega, C., Goff, H. D., \& Kos, Y. H. (2005). Spray drying of high-sucrose dairy emulsions: feasibility and physicochemical properties. Journal of Food Science, 70(3), 244-251. 